Sir,

\section{Response to Park et al}

We would like to thank Park et $a l^{1}$ for their response to our original correspondence. ${ }^{2}$ The original aim of the survey was to obtain a snapshot of endophthalmitis rates in the UK following 23-gauge transconjunctival sutureless vitrectomy (23G TSV). This survey took place for two reasons. The first was that at the time (early 2009), there was no previously published evidence from the UK on 23G TSV, although there was one publication on 20-gauge vitrectomy. ${ }^{3}$ The second reason was that although other published evidence from around the world had not found a significant difference in endophthalmitis rates between 20-gauge and 23-gauge vitrectomy, ${ }^{4-6}$ one published article had found a significantly higher rate (12 times greater than 20-gauge vitrectomy) in 25-gauge vitrectomy, ${ }^{7}$ and we were concerned that this would end up being extrapolated to 23-gauge vitrectomy, as both 23-gauge and 25-gauge techniques can be considered 'small gauge'.

We agree that a British Ophthalmic Surveillance Unit study should be considered as a gold standard for investigating rare complications, and are pleased to see that such a study is in progress for this topic. We look forward to the final results, and hope that they can confirm that endophthalmitis rates following 23G TSV are closer to published 20-gauge rates, rather than 25 -gauge rates.

\section{Conflict of interest}

The authors declare no conflict of interest.

\section{References}

1 Park JC, Ramasamy B, Ling RH, Prasad S. Endophthalmitis following vitrectomy. Eye 2012; 26: 482.

2 Patel KC, Rahman R. Incidence of post-operative endophthalmitis following 23-gauge transconjunctival sutureless vitrectomy in the United Kingdom: a survey. Eye 2011; 25: 956.

3 Mollan SP, Mollan AJ, Konstantinos C, Durrani OM, Butler L. Incidence of endophthalmitis following vitreoretinal surgery. Int Ophthalmol 2009; 29(3): 203-205.

4 Parolini B, Romanelli F, Prigione G, Pertile G. Incidence of endophthalmitis in a large series of 23-gauge and 20-gauge transconjunctival pars plana vitrectomy. Graefes Arch Clin Exp Ophthalmol 2009; 247(7): 895-898.

5 Schweitzer C, Delyfer MN, Colin J, Korobelnik JF. 23-Gauge transconjunctival sutureless pars plana vitrectomy: results of a prospective study. Eye 2009; 23(12): 2206-2214.

6 Lott MN, Manning MH, Singh J, Zhang H, Singh H, Marcus DM. 23-gauge vitrectomy in 100 eyes: short-term visual outcomes and complications. Retina 2008; 28(9): 1193-1200.

7 Kunimoto DY, Kaiser RS. Incidence of endophthalmitis after 20- and 25-gauge vitrectomy. Ophthalmology 2007; 114(12): 2133-2137.

KC Patel ${ }^{1}$ and R Rahman ${ }^{2}$

${ }^{1}$ Hull Royal Infirmary, Hull, UK

${ }^{2}$ Calderdale Royal Hospital, Halifax, UK

E-mail: karnesh@doctors.org.uk

or binarahman@fsmail.net

Eye (2012) 26, 483; doi:10.1038/eye.2011.330;

published online 16 December 2011 